\title{
Special aspects of modulation RCS measurement in $\mathrm{K}_{\mathrm{a}}$-band
}

\author{
Igor V. Kryuchkov, Eduard O. Mozharov*, and Anna I. Skachkova \\ Bauman Moscow State Technical University 5, 2nd Baumanskaya Str., 105005, Moscow, Russia
}

\begin{abstract}
Radar reflectors are used as standards for radioelectronic devices calibration, as navigation beacons for air and naval traffic control and for radar visibility increase. Controlled (parametric) reflectors change reflected signal characteristics. This leads to appearance of easily detectable additional frequency components on modulation frequency. $\mathrm{K}_{\mathrm{a}}$-band parametric reflector design, consisting of horn reflector and phase switch $0^{\circ} / 180^{\circ}$ board, is suggested. Technique of parametric reflector modulation RCS measurement, using complex envelope of reflected signal in every phase switch state, is suggested. Measuring bench description is given. Comparative analysis of theoretical calculations and experimental results is carried out. Accuracy of modulation RCS measurement according to the said technique is obtained experimentally. Measurements accuracy constraints are detected.
\end{abstract}

\section{Introduction}

Parametric reflectors - a special kind of reflectors, which change characteristics of reflected signal in time - are used worldwide for moving target imitation and reflector detection on background clutter. Parametric reflectors can be based on reflective antennas, whose load impedance changes according to a specific rule [1-3].

Complex-valued reflection coefficient and corresponding reflector radar cross section (RCS) change along with load impedance. There occur amplitude and phase modulation of reflected signal, that leads to additional frequency components in reflected signal. Two components can be identified in parametric reflector RCS: RCS on carrier frequency and equivalent modulation RCS on the other frequencies (as a rule they correspond to the modulation signal harmonic components). Modulation RCS component is specifically important for parametric reflectors.

In case of sufficient transformation frequency this harmonic components can be detected. It makes it possible to pick out a point on background due to its frequency shift, other than big RCS.

The vast majority of papers review different aspects of monostatic RCS measurements of various reflector designs. This paper describes $\mathrm{K}_{\mathrm{a}}$-band parametric reflector design. A modulation RCS measurement routine is given. $\mathrm{K}_{\mathrm{a}}$-band parametric reflector modulation RCS calculation data and measurement experimental results are given.

\section{Subject of research and routine of an experiment}

In parametric reflector design two main parts may be distinguished [1-4]: antenna and reflected signal modulator. The choice of parametric reflector antenna is based on electric, weight-and-dimensional and technological requirements.

* Corresponding author: eduardmozharov@yandex.ru 
The choice of reflected signal modulator provides the greatest difference between reflection coefficients in on and off state.

\subsection{Calculation of parametric reflector electrical requirements}

Antenna electrical characteristics rely on required modulation RCS level and in-band backward scatter indicatrix main lobe beamwidth at $-3 \mathrm{~dB}$. Analytic expression (1) for plane reflector RCS can be used for modulation RCS evaluation [4].

$$
\sigma=4 \pi \frac{S^{2}}{\lambda^{2}}
$$

where $\sigma$ is the RCS, $\mathrm{m}^{2} ; S$ is the plane reflector area, $\mathrm{m}^{2} ; \lambda$ is the wavelength in free space, $\mathrm{m}$.

The effective antenna area is equivalent to the plane reflector area. Modulation RCS is calculated upon the formula (2) with allowance for reflected signal loss in antenna and modulator. Antenna loss is taken into account twice, since the signal passes the antenna both at transmittion and reception.

$$
\sigma_{\text {mod }}=4 \pi \frac{S_{\text {ea }}^{2}}{\lambda^{2}} \cdot\left(1-L_{\mathrm{a}}\right)^{2} \cdot\left|0.5 \cdot\left(\Gamma_{\bmod 1}-\Gamma_{\bmod 2}\right)\right|^{2}
$$

where $\sigma_{\text {mod }}$ is the modulation RCS, $\mathrm{m}^{2} ; S_{e a}$ is the effective antenna area, $\mathrm{m}^{2} ; L_{a}$ is the dissipative losses; $\Gamma_{\bmod 1}, \Gamma_{\bmod 2}$ are the reflected signal modulator reflection coefficients in first and second state.

Backward scatter indicatrix main lobe beamwidth of at $-3 \mathrm{~dB}$ is equal to directional diagram main lobe beamwidth at $-1,5 \mathrm{~dB}$, as reception and reflected signal transmission occur at the same angular direction.

\subsection{Parametric reflector design}

Subject of research is a $\mathrm{K}_{\mathrm{a}}$-band parametric reflector, which is shown at Fig. 1a. Reflector 3 -D sectional view is shown at Fig. 1b, where 1 is holddown clamp, 2 is fluoroplastic band, 3,4 , and 5 are milled horn antenna parts, 6 is the short-circuitor, 7 is on-board switch, 8 is control connection.

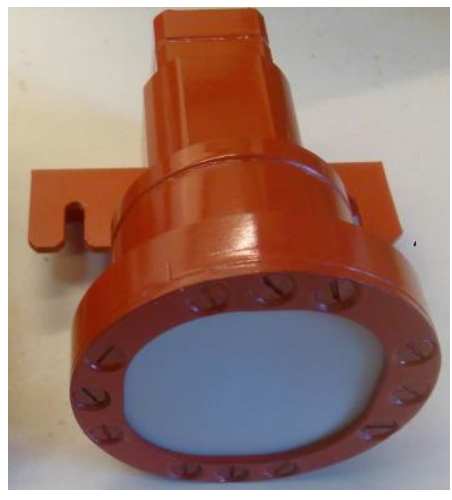

$\mathrm{a}$

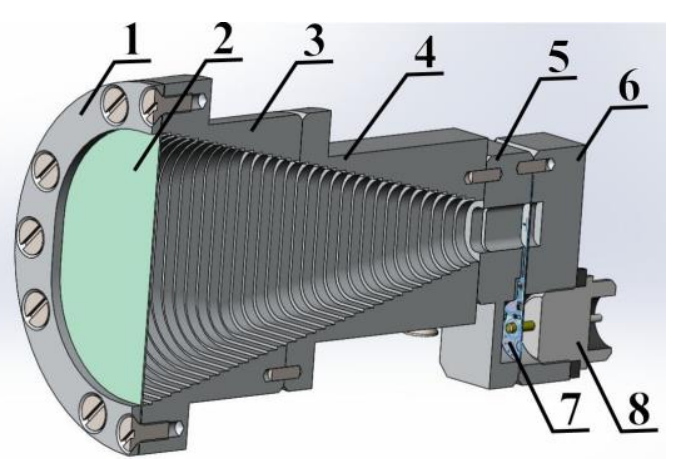

b

Fig. 1. Complete $\mathrm{K}_{\mathrm{a}}$-band parametric reflector (a) and its 3-D sectional view (b). 
In a reflector of described design phase switch pin diodes can be in open («on») or closed («off») state (see Fig. 2). In this case RCS of an equivalent reflector, which generate only signal phase keying $0^{\circ} / 180^{\circ}$, is taken as modulation RCS.

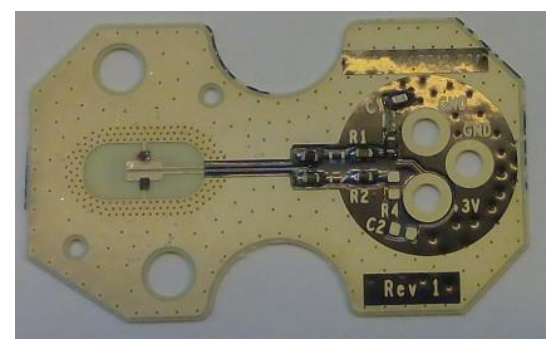

Fig. 2. Phase switch board.

It should be noted that particular design can be modified for N-position phase keying $(\mathrm{N}>2)$, for example, $0^{\circ} / 90^{\circ} / 180^{\circ} / 270^{\circ}$ etc.

\section{Modulation RCS measurement routine}

Modulation RCS measurement was carried out on dissipation characteristics measuring bench [4] in anechoic chamber. Measuring bench is based on vector network analyzer and measures reflector coeffitient $\mathrm{S} 11(f)$. in $16 \mathrm{GHz}$ band succeeded by processing in time domain [5,6] with elimination of extraneous reflections. Main measuring bench characteristics are shown in Table 1.

Table 1. Measuring bench characteristics.

\begin{tabular}{|c|c|}
\hline Characteristic & Value \\
\hline Bandwidth, GHz & 16 \\
\hline Polarization & linear \\
\hline Distance between objects, $\mathrm{m}$ & 4,4 \\
\hline Number of measured points per band & 1601 \\
\hline IF bandwidth, GHz & 1 \\
\hline Time window, ns & 3 \\
\hline Transmitted power, $\mathrm{dBm}$ & 0 \\
\hline Measured parameter & $\mathrm{S} 11$ \\
\hline
\end{tabular}

Firstly a search for time interval, where the object of interest can be found, is carried out. Object response location in time domain is determined on the basis of the distance to the object and microwave path length. Time domain diagrams with and without object of interst are shown on Fig. 3, 4.

In area "1" of time domain diagrams only thermal noise is present. Its level depends mainly on IF bandwidth. In area "2" on the Fig. 3 a response of parametric reflector in «on» state is present. On the Fig. 4 this response is absent. In area "3" on both figures a wide response from dissipating radar-absorbent walls is visible. When object of interest is located in measuring zone, weak additional $-100 \mathrm{~dB}$ response, resulting from secondary reflection from antenna pedestal, appears.

Secondly measuring bench calibration is carried out. Thereto level of signal, received from standards (reference reflectors) in band, is estimated. Laboratory standards are shown at Fig. 5. 50 and $100 \mathrm{~mm}$ diameter metal balls were used as reference reflectors. Time domain diagram of signal, reflected from a $50 \mathrm{~mm}$ diameter metal ball, is shown at Fig. 6.

When theoretical and experimental RCS of reference reflectors are equalized in band with $0.5 \mathrm{~dB}$ tolerance, measuring bench is calibrated for further RCS measurements. 


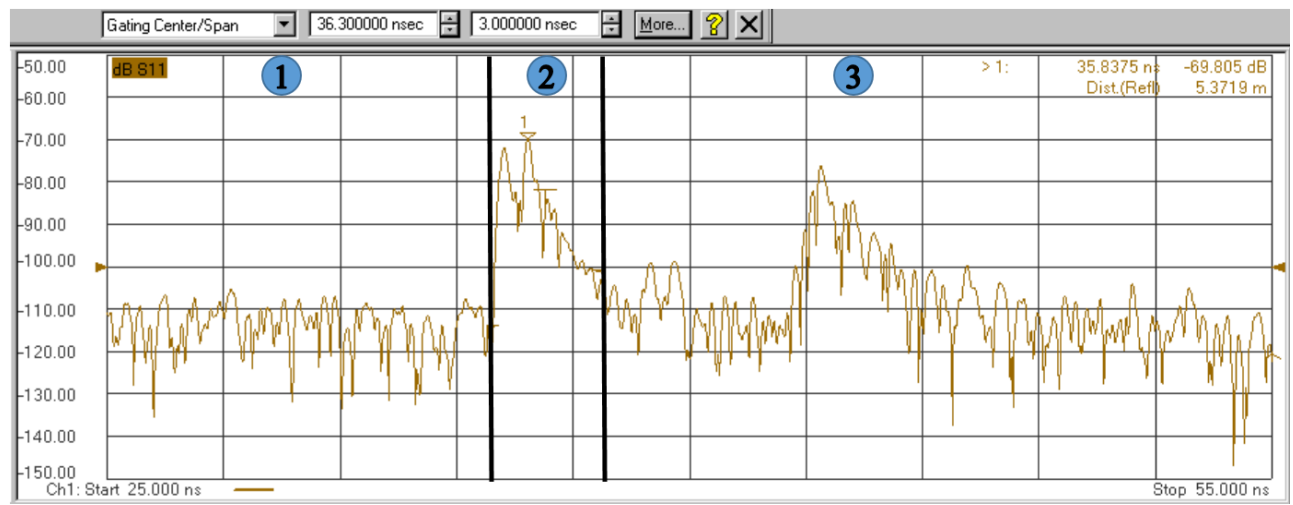

Fig. 3. Reflected signal time domain diagram with parametric reflector in «on» state, made with the measuring bench.

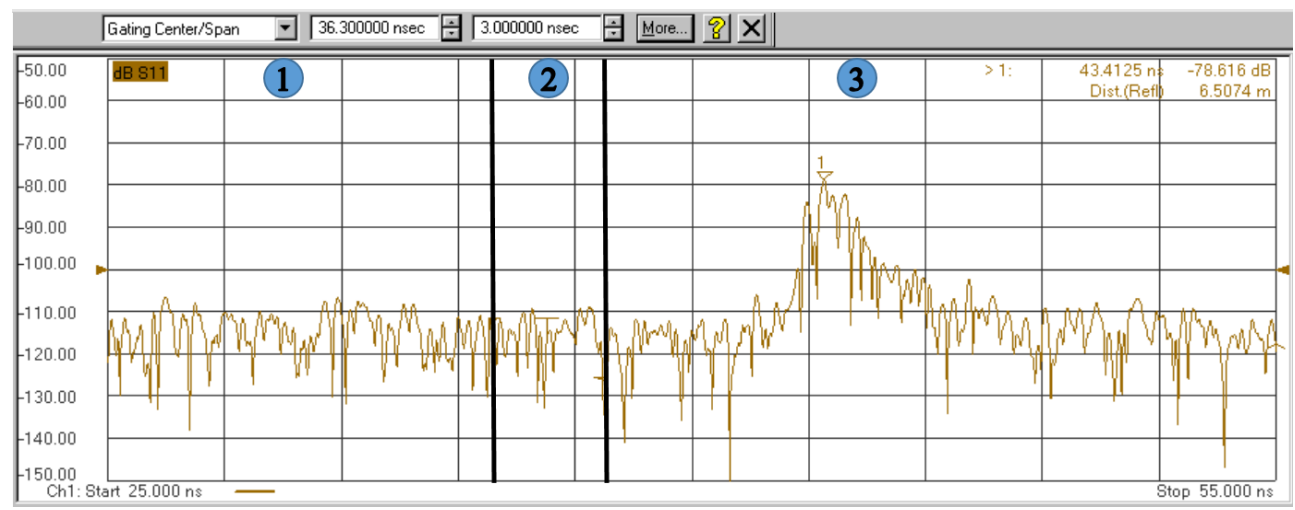

Fig. 4. Reflected signal time domain diagram without parametric reflector, made with the measuring bench.

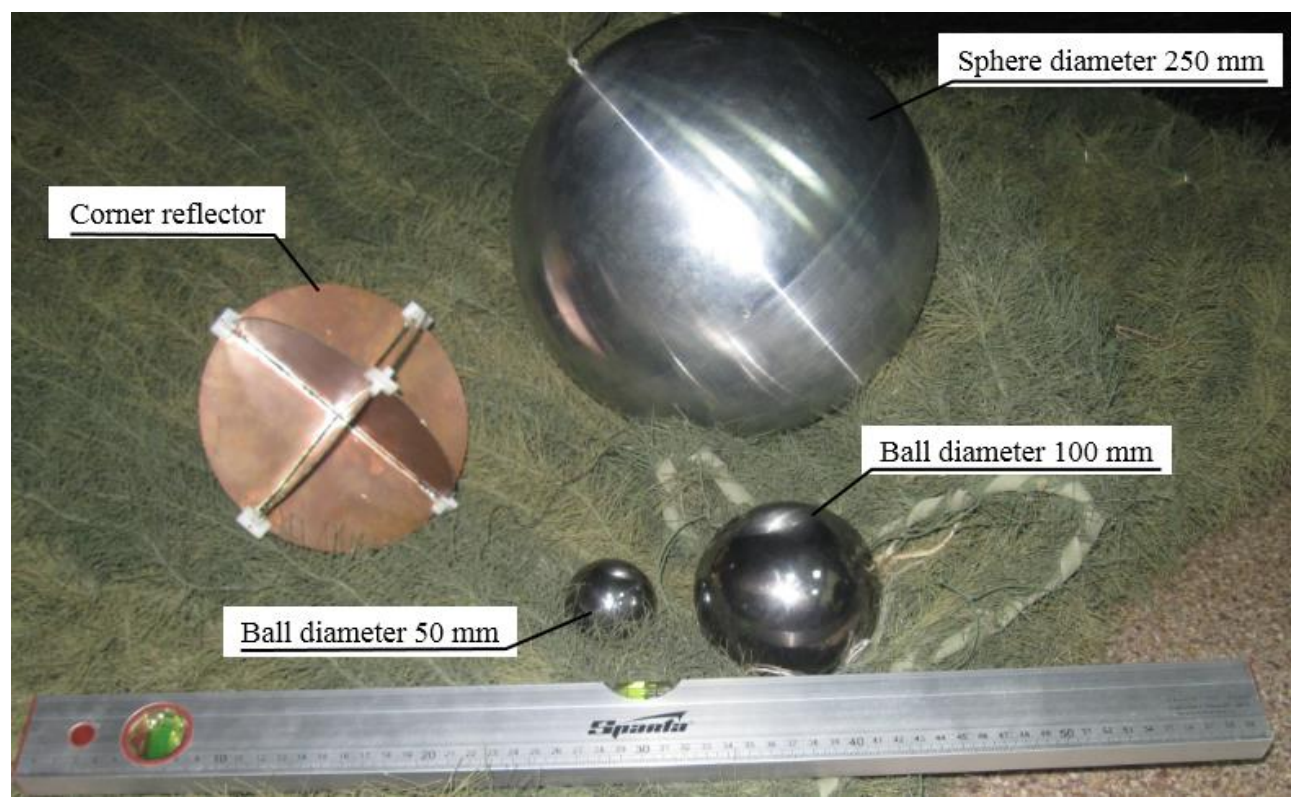

Fig. 5. Reference reflectors used for RCS measurements. 


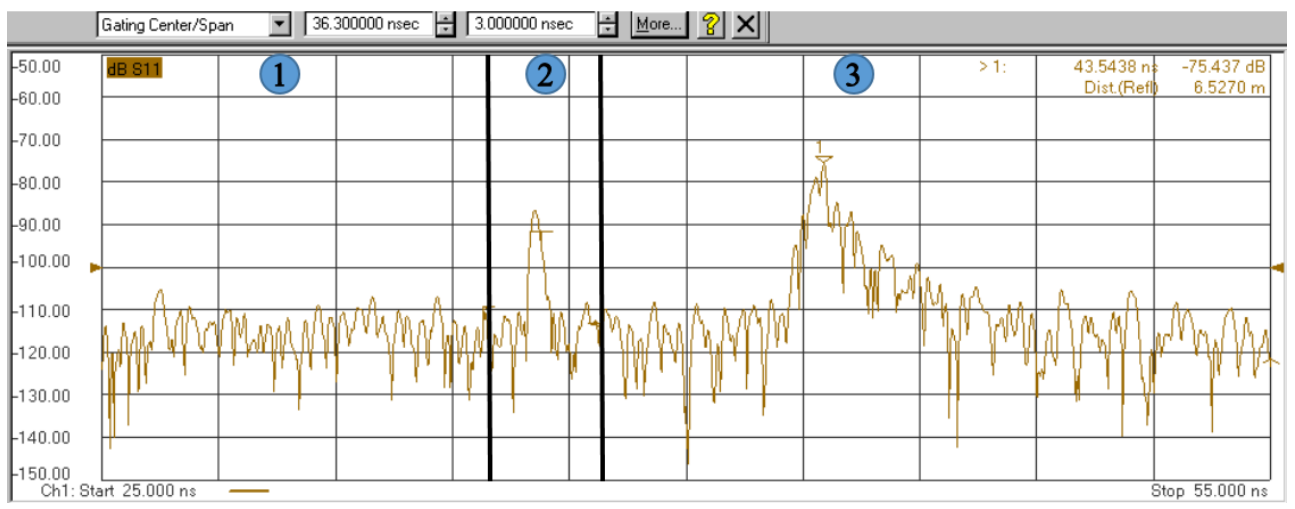

Fig. 6. Reflected signal time domain diagram with with $50 \mathrm{~mm}$ diameter metal ball, made with the measuring bench.

Thirdly parametric reflector is brought back to the measuring bench and a set of measurements in axial direction in both phase switch states is carried out. Reflected signal complex envelope $\Gamma(f)$, related to the object of interest, is calculated upon the formula (3). Due to applied processing specificities opening and ending spectrum $\Gamma(f)$ areas are excluded, as useful signal is being rejected by noise [5].

$$
\Gamma(f)=\mathrm{F}\left\{\mathrm{G}(t) \cdot \mathrm{F}\{\mathrm{S} 11(f) \cdot \mathrm{W}(f)\}^{-1}\right\}
$$

where $\mathrm{F}\{\}$ is the forward Fourier transformation; $\mathrm{F}\{\}^{-1}$ is the inverse Fourier transformation; $\mathrm{W}(f)$ is Kaiser window function [7]; $\mathrm{G}(t)$ is the time window.

Data for monostatic modulation RCS calculation is obtained by object of interest rotaion on antenna pedestal in azimuthal plane with fixed angular step. Reflection coeffitient from parametric reflector in both phase switch states is determined in each angular position.

\section{Modulation RCS calculation on experimental basis}

In-band parametric reflector modulation $\operatorname{RCS} \sigma_{\bmod }(f)$ is calculated upon the formula (4) according to experimental complex envelopes of signals, reflected from the standards and parametric reflector in different phase switch states.

$$
\sigma_{\text {mod }}(f)=\sigma_{\text {std }}(f) \cdot\left(0,5 \cdot\left|\Gamma_{\text {on }}(f)-\Gamma_{\text {off }}(f)\right| /\left|\Gamma_{\text {std }}(f)\right|^{-1}\right)^{2}
$$

where $\sigma_{\text {std }}(f)$ is the theoretical reference reflector $\operatorname{RCS}[4] ; \Gamma_{\text {std }}(f)$ is the standard reflected signal complex envelope; $\Gamma_{\text {on }}(f)$ and $\Gamma_{\text {off }}(f)$ are complex envelopes of signals, reflected from parametric reflector in «on» and «off» states accordingly.

In-band parametric reflector modulation RCS diagram is shown at Fig. 7.

Monostatic modulation RCS are determined in preset band for parametric reflector Eand H-planes with angular coverage from -10 to 35 degrees with one degree step. Theoretical and experimental normalized monostatic modulation RCS comparison in $\mathrm{H}$ plane at frequency $f_{0}$ is shown at Fig. 8 .

Experimental monostatic modulation RCS agrees with theoretical. Fig. 8 shows, that measuring bench sensitivity is $21 \mathrm{~dB}$ below modulation RCS maximum $\left(580 \mathrm{~cm}^{2}\right)$ at frequency $f_{0}$. This leads to the conclusion that the measuring bench is applicable for RCS measurement $4,6 \mathrm{~cm}^{2}$ onwards. Taking into account calibration relative accuracy $\pm 0.5 \mathrm{~dB}$ and deviation from theoretical diagram $\pm 0,2 \mathrm{~dB}$, relative modulation RCS measurement accuracy is estimated at $\pm 0,7 \mathrm{~dB} 4.6 \mathrm{~cm}^{2}$ onwards. 


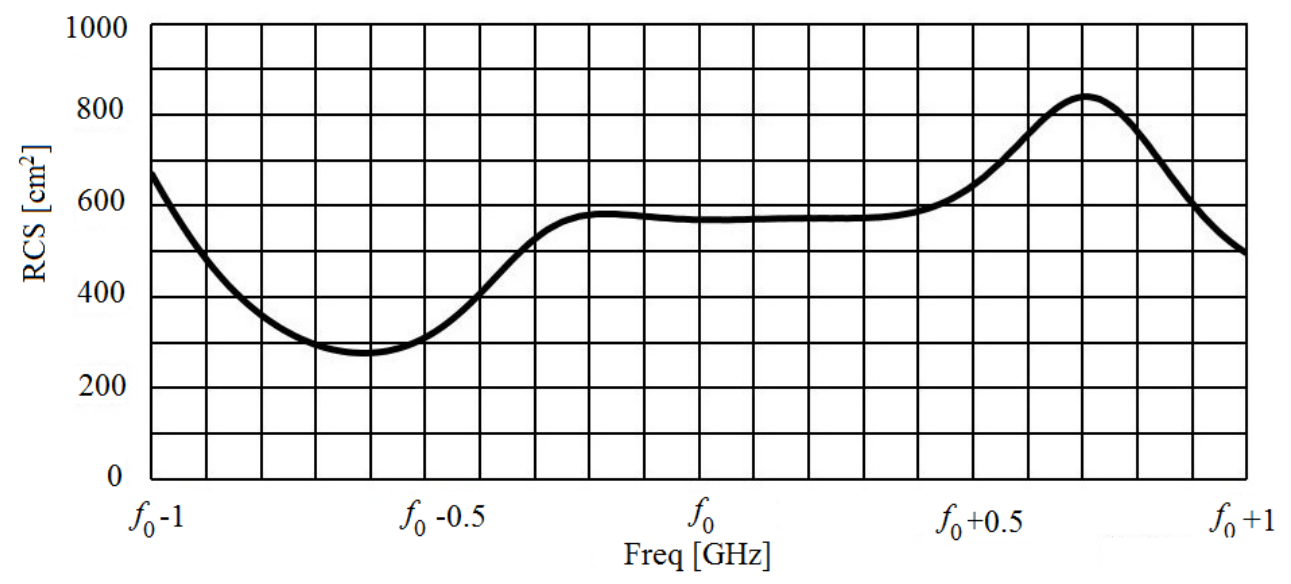

Fig. 7. Parametric reflector modulation RCS diagram.

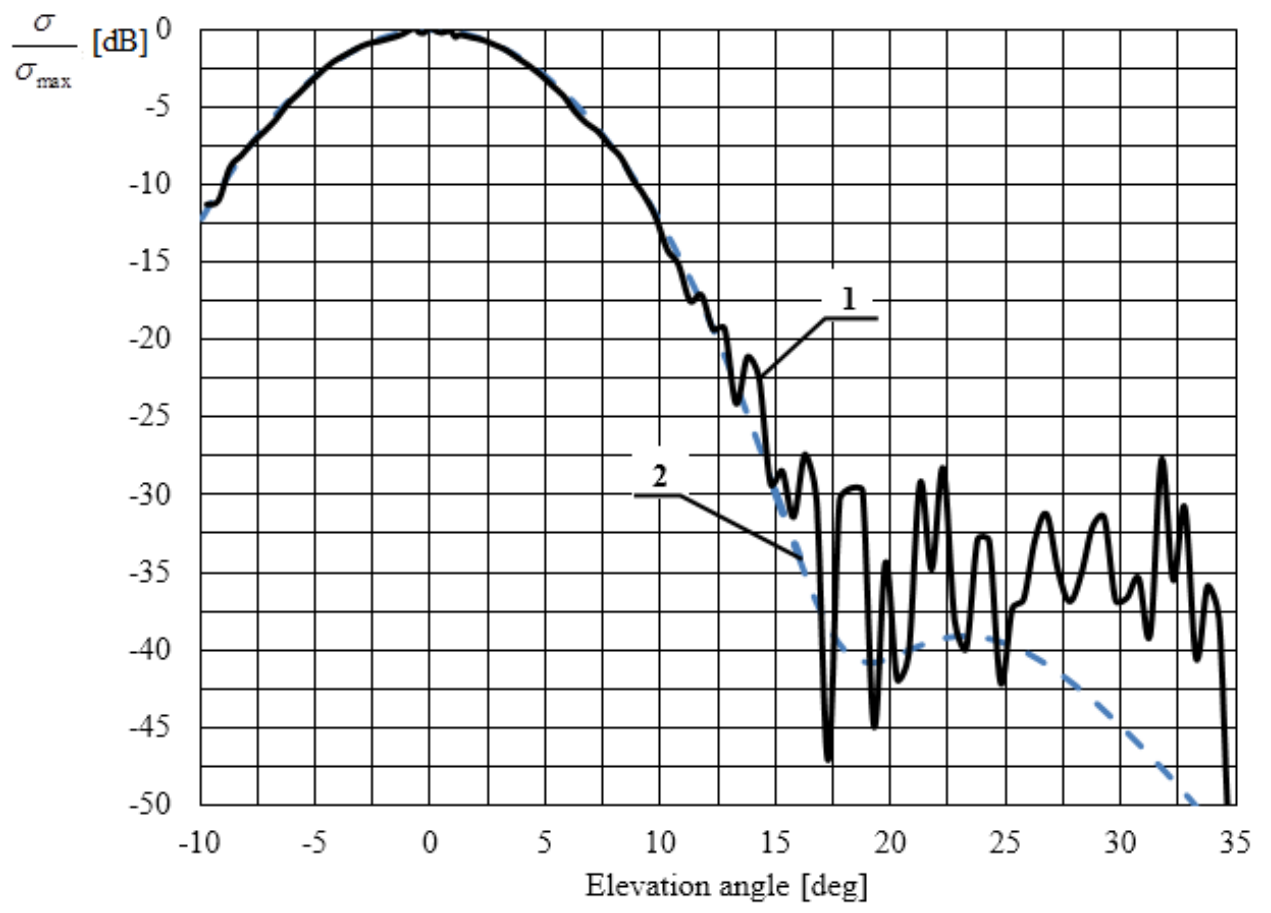

Fig. 8. Normalized H-plane monostatic modulation RCS at frequency $f_{0}$ :

1 - experimental; 2 - theoretical.

\section{Conclution}

$\mathrm{K}_{\mathrm{a}}$-band parametric reflector is designed and manufactured. Measuring bench for monostatic dissipation characteristics in $\mathrm{K}_{\mathrm{a}}$-band measuring is designed and accembled. The technique of parametric reflector modulation RCS determinig, based on reflected signal complex envelope measurement, is suggested. Parametric reflector modulation RCS in $\pm 1 \mathrm{GHz}$ band is obtained due to experimental measurements of reflection coeffitients in different phase switch states. Relative accuracy of binary phase keying parametric reflector 
modulation RCS determination is is estimated at $\pm 0,7 \mathrm{~dB} 4.6 \mathrm{~cm}^{2}$ onwards. Suggested technique can be modified for N-position phase keying parametric reflector modulation RCS determination. In this case reflected signal complex envelope, corresponding to each state of N-position phase keying constellation, is required for modulation RCS estimation.

\section{References}

1. Chisholm J.P. Frequency shift reflection system. USA-Patent, Cl. 343-18, No. 3108275, filled 1960, patented 1963.

2. Zaleski J.F. Passive beacon. USA-Patent, Cl. 343-18, No. 3159836, filled 1960, patented 1963.

3. Nefedov S.I., Shustikov V.YU., Slukin G.P., Baturin A.S., Kuznetsov A.A., Kryuchkov I.V. Reference parametric reflector. Patent Russia, Cl. 2004137843, No. 2277741, filled 24.12.2004, patented 10.06.2006. (In Russ.)

4. Kobak V.O. Radiolokatsionnye otrazhateli [Radar reflectors]. Радиолокационные отражатели. Moscow, Sovetskoe radio Publ., 248 p. (In Russ.) (1975)

5. Mozharov E.O., Galkin N.K. Calibration of a broadband test bench for measuring the scattering characteristics of object. Journal of Radio Electronics. 2018, no. 10. Available at: http://jre.cplire.ru/jre/oct18/11/text.pdf. (accessed 14 August 2019) (In Russ.)

6. Joel P. Dunsmore. Handbook of Microwave Component Measurements: with Advanced VNA Techniques. John Wiley and sons, 2012, 636 p. (Russian ed. : Dunsmore Joel P. Дансмор Джоэль П. Nastol'naya kniga inzhenera. Izmerenie parametrov SVCHustrojstv s ispol'zovaniem peredovyh metodik vektornogo analiza tsepej. Moscow, Tekhnosfera Publ., 736 p.) (2018)

7. Dvorkovich V.P., Dvorkovich A.V. Okonnye funktsii dlya garmonicheskogo analiza signalov [Window functions for signal harmonic-measurement]. Moscow, Tekhnosfera Publ., 208 p. (2016) 